\title{
PSICOLOGIA FORENSE EM EVOLUÇÃO: UMA ANÁLISE DA (IN)CAPACIDADE NA INTERPRETAÇÃO DADA PELA LEI 13.146/2015
}

\author{
DOI: 10.22289/2446-922X.V6N2A5
}

\author{
Constance Rezende Bonvicini ${ }^{1}$ \\ Júlio Alves Caixêta Júnior \\ Rosangela Silva Sousa
}

\section{RESUMO}

O presente trabalho acadêmico apresenta um estudo sobre a questão da capacidade e incapacidade; referenciando desde a luta antimanicomial à atuação do psicólogo forense, Ordenamento jurídico, retratando a atualidade das leis, tratada no Livro I, Das Pessoas, Título I, Das Pessoas Naturais do Código Civil 2002, Lei 10.406, Capítulo I Da Personalidade e da Capacidade. Considera ainda a abordagem dada pela Lei 13.146 de 2015, Lei Brasileira de Inclusão da Pessoa com Deficiência (Estatuto da Pessoa com Deficiência). Dessa forma, a pretensão do estudo está em suscitar a co-responsabilidade do psicólogo forense como auxiliar na delimitação dos casos, sobretudo para avaliação de incapacidade relativa, suscitando as causas transitórias ou permanentes, com foco nas causas transitórias. Estudo fundamentado no Artigo $4^{0}$ e seus incisos I, II, III, IV, todos do Código Civil vigente, com leitura atual dada pelo Estatuto em ordem. Concluindo-se que a sistemática das incapacidades passou a ser flexibilizada, que com certa maleabilidade passou a pensar as circunstâncias do caso concreto e suas peculiaridades, para então operar tutelando a dignidade, a interação social e a inclusão de pessoas.

Palavras-chave: Psicologia Forense; Deficiência; Capacidade; Incapacidade Transitória.

\section{EVOLUING FORENSIC PSYCHOLOGY: AN ANALYSIS OF (IN)CAPACITY IN THE INTERPRETATION GIVEN BY LAW $13.146 / 2015$}

\section{ABSTRACT}

This present academic paper presents a study on the question of capacity and disability; referring to the anti-manicomal fight, the performance of forensic psychologist in conjunction with the legal, portraying the currentness of the laws, dealt with in Book I, Of People, Title I, Of Natural People of the Civil Code 2002, Law 10.406, Chapter I Of Personality and Capacity. It considers the approach given by Law 13,146 of 2015, Brazilian Law for the Inclusion of Persons with Disabilities (Statute for Persons with Disabilities). The intention of the study is to raise the coresponsibility of forensic psychologist as an aid in the delimitation of cases, especially in the assessment of relative disability, raising temporary or permanent causes, focusing on transitory causes. Study based on Article 4 and its items I, II, III, IV, all of the current Civil Code, with current reading given by the

\footnotetext{
${ }^{1}$ Endereço eletrônico de contato: constancebonvicini@yahoo.com.br Recebido em 11/04/2020. Aprovado pelo conselho editorial para publicação em 09/06/2020.
} 
Statute in order. In conclusion, the systematic of disabilities started to be made more flexible, which with a certain malleability began to think about the circumstances of the specific case and its peculiarities, to then operate safeguarding dignity, social interaction and the inclusion of people.

Keywords: Forensic Psychologist; Deficiency; Capacity; Transitory Disability.

\section{PSICOLOGIA FORENSE EM EVOLUÇÃO: UMA ANÁLISE DA (IN) CAPACIDADE NA INTERPRETAÇÃO DADA PELA LEI 13.146 / 2015}

\section{RESUMEN}

El presente trabajo académico presenta un estudio sobre la cuestión de la capacidad y la discapacidad; refiriéndose a la lucha contra el asilo, el desempeño de los psicólogos forenses en conjunto con lo legal, retratando la actualidad de las leyes, tratadas en el Libro I, De las personas, Título I, De las personas naturales del Código Civil 2002, Ley 10.406, Capítulo I de Personalidad y Capacidad. Considera el enfoque dado por la Ley 13.146 de 2015, Ley brasileña para la inclusión de las personas con discapacidad (Estatuto para las personas con discapacidad). La intención del estudio es aumentar la coresponsabilidad de los psicólogos forenses como una ayuda en la delimitación de casos, especialmente en la evaluación de la discapacidad relativa, planteando causas temporales o permanentes, centrándose en causas transitorias. Estudio basado en el Artículo 4 y sus ítems I, II, III, IV, todo el Código Civil vigente, con la lectura actual dada por el Estatuto en orden. En conclusión, la sistemática de discapacidades comenzó a hacerse más flexible, lo que con cierta maleabilidad empieza a pensar en las co=ircustancias del caso específico y sus peculiaridad, para luego operar slvaguardando la dignidad, la interacción social y la inclusión de las personas.

Palabras clave: Psicólogo Forense; Discapacidad; Capacidad; Discapacidad Transitória.

\section{INTRODUÇÃO}

Pessoas todos somos, se capazes, o Ordenamento Jurídico vai dizer. Para tanto é necessário que um conjunto de profissionais, interligados ao sistema jurídico, trabalhem em prol de acumularem evidências de que a pessoa apresente dificuldades para tomar decisões coerentes com o exercício da cidadania, com o exercício de seus direitos civis. Estabelece o Código Civil vigente em seu artigo primeiro que: "Toda pessoa é capaz de direitos e deveres na ordem civil" (Brasil, 2002). Analogamente, o Código Civil de 1916 em seu segundo artigo, restringia o conceito de pessoa sujeita de direitos a: "Todo homem é capaz de direitos e obrigações na ordem civil" (Brasil, 2016). Com efeito manifesto, o atual Código Civil amplia a conceituação de pessoas capazes, de forma que pessoa representa todo gênero humano, inserido em um contexto sócio-histórico, conceito que era restritivo e arcaico na previsão do Código Civil de 1916. Tem-se então que, o princípio da igualdade das pessoas é tomado em proporção pelo que institui o regime da capacidade jurídica para os atos da vida civil.

Rev. Psicol Saúde e Debate. Set., 2020:6(2): 62-79. 
Conceitua-se capacidade como "aptidão para adquirir direitos e exercer, por si ou por outrem, atos da vida civil" (Monteiro \& Pinto, 2009). Nos dizeres dos nobres autores sobre o assunto, Washington de Barros e Ana Cristina de Barros Monteiro, capacidade é um elemento da personalidade jurídica, condensado na totalidade da pessoa, ente capaz de direitos e obrigações. "Capacidade exprime poderes ou faculdades; personalidade é a resultante desses poderes; pessoa é o ente a que a ordem jurídica outorga esses poderes” (Monteiro \& Pinto, 2009). Ressalta-se que "A personalidade civil da pessoa começa do nascimento com vida", assim impõe o Código Civil que nos ampara hodiernamente (Brasil, 2002).

Tem-se que a Incapacidade é a insuficiência das condições imprescindíveis para o exercício dos direitos e deveres da pessoa. É a restrição da Lei para o efetivo exercício dos atos da vida civil e ainda a ausência de discernimento para a prática do ato e ou negócio jurídico, ausência de preceitos que corroborem para a devida tomada de decisão nos meandros da vida civil.

Toda e qualquer incapacidade, absoluta ou relativa, sobrevém da lei, necessitando da interdição ${ }^{2}$ para a declaração de incapacidade, salvo, a presunção legal de incapacidade dada aos menores, sendo absoluta para o menor de dezesseis anos e relativa para o menor de dezoito e maior que dezesseis anos. A declaração da incapacidade não impede a prática de atos da vida civil, somente condiciona o seu exercício por meio da representação ou assistência.

Abordando a questão da Teoria das Capacidades, Nelson Rosenvalde e Cristiano Chaves Farias, esclarece que a ideia fundamental de que a capacidade é a regra e a incapacidade, a exceção, surge o direito positivo que contempla objetivamente, as hipóteses de restrição da plena capacidade, esclarecendo ser excepcional a limitação ao exercício dos atos civis. De forma efetiva, "a incapacidade é o reconhecimento da inexistência, numa pessoa, daqueles requisitos que a lei acha indispensáveis para que ela exerça os seus direitos" (Rosenvalde \& Farias, 2014).

Sendo a capacidade a regra, necessário se faz determinar as causa que promovem a incapacidade, assim, necessário a apresentação do conceito de deficiência - além do conceito de doença mental - expresso no artigo segundo do Estatuto da Pessoa com Deficiência, conceito

\footnotetext{
${ }^{2}$ Nota Explicativa: Teoria das Incapacidades: segundo Nelson Rosenvald: o Estatuto da Interdição, um instituto jurídico surgido no século XIX na Alemanha como uma via processual para neutralizar a capacidade civil da pessoa, daí a justificativa do Direito Civil para legitimar esse paradigma de exclusão vem do jurista alemão Friedrich Carl Von Savigny $(1779$ - 1861), da Escola Pandectista, que criou a teoria das incapacidades. "Savigny, em um esquema artificial de laboratório, dividiu o mundo em três níveis, e os seres humanos em três categorias, do céu ao inferno, passando pelo purgatório. Ele colocou no céu os absolutamente capazes, que são aquelas pessoas que têm livre trânsito nas relações econômicas; alojou no purgatório os relativamente incapazes, que eram aquelas pessoas assistidas ou auxiliadas para a prática dos atos da vida civil; e, finalmente, pôs no inferno os absolutamente incapazes, que eram aquelas pessoas representadas pelos seus curadores, completamente substituídas no exercício dos atos da vida civil, sejam patrimoniais ou existenciais". ROSENVALD, Nelson. EPM conclui o curso "Temas atuais do Direito das Famílias e das Sucessões", Revista Eletrônica da Escola Paulista da Magistratura, $n^{\circ}$ 225, 2016. Disponível em: <http://epm.tjsp.jus.br/Noticias/noticia/34766>. Acesso em 25 fevereiro de 2020.
}

Rev. Psicol Saúde e Debate. Set., 2020:6(2): 62-79. 
este para atender o proposto na Convenção de Nova York, sobre a temática do Direito das Pessoas com deficiência, em consonância com o Estatuto em estudo. O Artigo Segundo prevê no Estatuto da Pessoa com Deficiência, Lei 13.146/2015:

"Art. $2^{\circ}$ Considera-se pessoa com deficiência aquela que tem impedimento de longo prazo de natureza física, mental, intelectual ou sensorial, o qual, em interação com uma ou mais barreiras, pode obstruir sua participação plena e efetiva na sociedade em igualdade de condições com as demais pessoas" (Brasil, 2015).

Traçar a incapacidade de uma pessoa e pontuar sua higidez mental é tarefa complexa, haja visto que, mesmo com o auxílio da psicologia forense, ciência que estuda o comportamento e os processos mentais aplicados ao contexto forense, pode se fazer insuficiente e não contar com meios suficientemente adequados para aferir a capacidade ou incapacidade de um indivíduo, sobretudo nas doenças mentais, em que os quadros são instáveis e com variações diversas, incluindo os quadros que possuem comorbidades, como diferentes deficiências. Nos casos de deficiência mental os quadros são mais estáveis, e, portanto, apresenta mais clareza para serem delimitados.

Dada a repercussão jurídica do resultado da avaliação em tela, a preocupação do legislador é delinear as hipóteses, a proteção jurídica e o instituto aplicável a cada caso; tendo em vista que "A avaliação psicológica é um conjunto de métodos e técnicas que pode identificar e caracterizar uma variedade de respostas comportamentais sobre diferentes aspectos das atitudes humanas" (Androvandi, Serafini, Trentini, \& Coelho, 2007). Dessa forma, no presente artigo, a pretensão está em suscitar a co-responsabilidade do psicólogo forense como auxiliar na delimitação dos casos, sobretudo para avaliação de incapacidade relativa, suscitando as causas transitórias ou permanentes, com foco nas causas transitórias. Estudo fundamentado no Artigo $4^{0}$ e seus incisos I, II, III, IV, todos do Código Civil vigente, com leitura atual dada pelo Estatuto em ordem.

\section{MÉTODOS}

Para a realização deste trabalho acadêmico foram feitas pesquisas bibliográficas, doutrinárias, jurisprudenciais, por meio de uma metodologia indutiva bibliográfica, construindo um estudo criterioso acerca da capacidade e da incapacidade civil da pessoa, a partir do artigo primeiro e seguintes do Código Civil Brasileiro vigente, perpassando os grandes doutrinadores que consolidam os conceitos trabalhados. Em último a abordagem do tema tratado pela lei 13.146/2015 denominada de Estatuto da Pessoa com Deficiência. Perfazendo uma conceituação analítica bibliográfica.

Rev. Psicol Saúde e Debate. Set., 2020:6(2): 62-79. 


\section{PSICOLOGIA FORENSE}

A Psicologia Forense é o subconjunto da Psicologia Jurídica, em que se incluem as práticas psicológicas relacionadas aos procedimentos forenses, serviços de perícia, em que se encontra o assistente técnico. A Psicologia Forense corresponde a toda aplicação do saber psicológico realizada sobre uma situação que se sabe estar (ou estará) sob apreciação judicial, ou seja, a toda a Psicologia aplicada no âmbito de um processo ou procedimento em andamento no Foro (ou realizada vislumbrando tal objetivo). Incluem as intervenções exercidas pelo psicólogo criminal, pelo psicólogo judiciário, acrescidas daquelas realizadas pelo psicólogo assistente técnico (Serafim, Barros, \& Rigonatti, 2006).

Dessa forma, Psicologia jurídica e Psicologia forense não são termos sinônimos, mas têm estreita ligação temática e prática. Assim, a Psicologia forense é uma área particular da Psicologia jurídica e que diz respeito diretamente às decisões e aos trabalhos que ocorrem nas situações de tribunais e de julgamentos. Já a Psicologia jurídica vai desde o estudo, passando pelo tratamento e pelo assessoramento de várias etapas da atividade jurídica, até o cuidado com vítimas, infratores e profissionais do Direito e equipes multidisciplinares.

Especificando-se sobre a área da psicologia forense é o ramo da psicologia que visa à aplicação dos conhecimentos psicológicos aos assuntos relacionados ao Direito, principalmente quanto à saúde mental, quanto aos estudos sócios-jurídicos e crimes, em que se avalia a personalidade das pessoas envolvidas. O profissional age junto à escritórios e o poder judiciário, com o intuito de que no contexto exista uma real ligação entre a Psicologia e o Direito. Hoje em dia a disciplina, muito aplicada na área criminal e social também, tem a função investigativa, analisando as condutas dos indivíduos. Psicossocialmente não se atentando somente a elaboração de laudos e análises técnicas como eram feitas até algum tempo atrás (Varela, Alvarez, \& Sarmiento, 2000).

O intuito primordial do psicólogo forense é munir advogados, juízes, desembargadores, promotores, procuradores, entre outros profissionais do Direito, de uma bagagem psicossocial e cultural sobre o comportamento humano para que as decisões tomadas em situações de tribunais sejam as menos injustas possíveis. Em disputas pela custódia dos filhos, por exemplo, é avaliada a autenticidade da opinião infantil a favor de um dos pais considerando-se condições sóciodemográficas, ou ainda, avalia se uma criança foi manipulada a emitir certa preferência ou se realmente está manifestando seu laço afetivo mais forte (Serafim, Barros, \& Rigonatti, 2006).

As avaliações realizadas pelos psicólogos forenses, entre outros atributos, podem contribuir para a decisão da retirada da criança da família ou da reintegração na mesma, do nível adequado de contato entre as crianças e os progenitores, da natureza e da extensão da 
intervenção e suporte familiar necessários para que as famílias prestem cuidados adequados aos filhos (Androvandi, Serafini, Trentini, \& Coelho, 2007).

Com efeito, o psicólogo forense é um profissional com treinamento adicional que deve incluir em sua formação a Psiquiatria e o Direito, o que the permite aplicar seus saberes às questões levantadas pelo sistema legal do seu local de atuação. Mais raramente pode acontecer uma prática clínica de emergência; alguns fóruns possuem serviço de apoio psicológico para disputas judiciais mais delicadas. Assim, o principal propósito da Psicologia forense é fornecer avaliações periciais que possam ser utilizadas por cortes, advogados e até mesmo por instituições de detenção. Ela também é bastante útil em situações que exijam a distinção entre um trauma ou perda dos sentidos psicológicos verdadeiro, detectando simulações. Tendo em vista que as desordens mentais graves autênticas podem conduzir à prática de algum delito involuntário. Nesse caso, necessário o conhecimento da vida do acusado (Varela, Alvarez, \& Sarmiento, 2000).

Acredita-se que os psicólogos forenses chegam até a cena do crime, examinam a área e, por fim, identificam várias pistas que vão ajudar a capturar o criminoso. Continuamente vê-se essas situações retratadas em programas de televisão, na mídia, em notícias e no cinema. $\mathrm{Na}$ verdade, sugere-se que essas imagens na mídia podem conduzir a inúmeras percepções incorretas sobre a psicologia forense em geral. Entretanto, os psicólogos não são convocados rotineiramente para coletar amostras de DNA, analisar uma amostra de sujeira deixada para obter a localização geográfica de onde ela se originou ou até para traçar os assim chamados perfis psicológicos. Psicologia forense também é bastante útil na elaboração de pareceres acerca da exploração sexual e de maus-tratos (Serafim, Barros, \& Rigonatti, 2006). Em oposição a tais situações mais comuns, o psicólogo forense ajuda a descobrir, por exemplo, se uma pessoa psiquicamente enferma se auto acusa ou se incrimina inocentemente por um delito grave levado a cabo por outrem. Portanto, o conceito recorrente em toda a prática da Psicologia forense é o "verdadeiro", ou seja, a potencialidade ou a escusa em se relatar a versão mais fiel possível dos fatos acontecidos.

Especificamente quanto a atividade cerebral da percepção, uma tarefa psíquica dinâmica, global e complexa. Retrata-se que, ainda que duas pessoas se deparem com mesma situação, elas a enxergarão de forma diferente, pois se trata de um processo subjetivo; logo, pessoal (Fiorelli \& Mangini, 2020). Naturalmente que existirão vários pontos em comum, mas definitivamente não terão uma visão idêntica do mesmo objeto, já que as influências dos costumes também são poderosas na determinação do processo perceptivo. Assim, poucos dados acerca de uma realidade já conhecida são suficientes para que o todo apareça na mente do indivíduo.

Também é importante para as questões jurídicas compreender a "amnésia emocional", já que grande parte dos eventos que chegam aos fóruns é negativa, do ponto de vista afetivo. Esse processo diz respeito àqueles indivíduos que, genuinamente, se tornam incapazes de se recordar Rev. Psicol Saúde e Debate. Set., 2020:6(2): 62-79. 
de situações e ocorrências traumáticas. Parti-se do pressuposto de que a maioria dos interrogatórios judiciais versa sobre eventos delituosos ou gira em torno de profunda carga emocional, entende-se a frequência da amnésia emocional nas vítimas, nas testemunhas e nos réus - mais raramente. O processo de esquecimento involuntário se dá porque a força da repressão sobre acontecimentos dolorosos age de forma inconsciente, numa tentativa de evitar um novo sofrimento com a rememoração (Serafim, Barros, \& Rigonatti, 2006).

Espera-se que quando o indivíduo é coagido a se lembrar de algo, ele então declara alguns fatos verídicos fragmentados e mesclados a fantasias, que são expostos não intencionalmente. No caso, é preferível deixar a cargo do indivíduo o fluxo da narração, ao invés do entrevistador ficar perguntando detalhes incisivamente, ou seja, incitando a descrever pormenores pode conduzi-lo à chamada "falsa memória". Até mesmo por haver a existência da chamada síndrome de Pirandello (Fiorelli \& Mangini, 2020). Logo, as averiguações em julgamento não devem induzir ao erro, sempre devem ser diretivas. Verifica-se, no entanto, que o relato espontâneo, frequentemente mais verídico, tem 0 aspecto negativo de ser relativamente incompleto e muitas vezes inconsistente e, além disso, pode ter "idas e vindas", a narração pode ser desuniforme e multilinear.

Em síntese, os dados coligidos pelos interrogatórios direcionados costumam ser mais concretos, mas, ao mesmo tempo, menos ricos. As narrações livres, por seu turno, são mais extensas, tem mais meandros, por isso mesmo podem ser mais confusas.

Por conseguinte, menciona-se que a única forma de mitigar o índice de mentiras (intencionais) ou enganos (inconscientes) existentes nos depoimentos das testemunhas é fazer um breve levantamento psicológico sobre o seu "apego" à verdade, em outras palavras, realizar uma sucinta avaliação de sua consciência moral. Para aquelas pessoas que decididamente têm o intuito de mentir ou maquinar histórias, só o juramento antes do inquérito ou as advertências sobre os riscos da falsidade ideológica não são mecanismos suficientes para inibir seu comportamento (Fiorelli \& Mangini, 2020).

A prática forense ainda aconselha que, caso se queira saber se alguém esteve realmente ou não no local de um crime, ao contrário de lhe perguntar de forma direta, pode-se perguntar sobre algum aspecto secundário do lugar e, de acordo com a resposta, é lícito deduzir se ela esteve lá ou não. Utiliza-se, ainda, o denominado método centrípeto, método pelo qual se alcança um ponto fundamental da questão a partir da periferia, através dele, quando mais afastada estiver uma pergunta do tema sob investigação, mais dificilmente o investigado terá razões para deformar uma resposta sobre ela (Serafim, Barros, \& Rigonatti, 2006). Além disso, os eventos corriqueiros, pelo fato de serem habituais, podem gerar respostas automáticas em relação a eles; correlativamente, as ocorrências distantes, que ocorreram no passado também podem originar versões distorcidas do que realmente aconteceu. Afirmando-se ainda que o fato de um episódio Rev. Psicol Saúde e Debate. Set., 2020:6(2): 62-79. 
ter despertado sentimentos negativos ou positivos em alguém pode causar viés, quando ele for relatado por esse indivíduo.

Exames psicológicos ainda têm demonstrado que certos perfis de personalidade fornecem respostas com "defeitos" similares; assim, indivíduos introvertidos tendem a conceder um discurso mais enxuto, todavia, mais objetivo. Indivíduos extrovertidos, por sua parte, são mais predispostos a serem influenciados por fatores do ambiente, mais exagerados, no entanto, a vantagem é que o discurso deles é rico em detalhes. No entanto, perante tais peculiaridades, não há relação direta entre o grau de introversão ou extroversão da personalidade com maior ou menor verdade das informações. Habitualmente, os tipos histéricos, os mitômanos (pessoas que mentem compulsivamente) e os paranoicos são os que mais mentem nos inquéritos. Os últimos são ótimos em projetar nos outros aspectos que desprezam em si próprios. Já os tipos compulsivoobsessivos, em função da forte autocensura que se infligem, são mais verídicos em seus testemunhos, apesar do sofrimento que demonstram, pois, todo o tempo estão se autocorrigindo (Androvandi, Serafini, Trentini, \& Coelho, 2007).

Tendo em vista esses transtornos e outras psicopatologias, durante os interrogatórios é importante que o juiz ou advogado esteja acompanhado de um psicólogo judicial com bom conhecimento de enfermidades psíquicas. Pois além da personalidade, também deve ser levado em consideração que o sexo do entrevistado, que influencia nas declarações, visto que o tipo de socialização diferenciada pela qual passam homens e mulheres, desde a infância, faz com que os primeiros sejam mais diretos, todavia menos ricos em pormenores, enquanto que as mulheres são mais complexas em suas narrações, contudo, mais confusas e sinuosas.

Em geral, os estudos da Psicologia jurídica envolvem um conceito básico, a moral, que pode ser definida como o conjunto de regras e padrões subjetivos informados socialmente que permitem ao indivíduo discernir o "bem" do "mal" (Serafim, Barros, \& Rigonatti, 2012). A moralidade seria então o lado "subjetivo" da conduta individual e, por sua vez, é sustentada pelo sistema axiológico mais amplo da sociedade. Sua esfera de estudo por excelência é a Ética, um dos campos específicos da Filosofia.

Historicamente, as primeiras aproximações da Psicologia com o Direito aconteceram no fim do século XIX, gerando a denominada "Psicologia do testemunho", que tinha como escopo verificar a fidedignidade e a veracidade dos relatos dos indivíduos arrolados num processo judicial, época em que o psicodiagnóstico era fundamentado unicamente em algumas entrevistas superficiais e nos resultados de testes psicológicos (Fiorelli \& Mangini, 2020). Em penitenciárias e hospitais psiquiátricos penais, tais exames serviam, entre outras coisas, para informar processos de livramento condicional ou se o detento mereceria uma progressão de regime.

Todavia, fortes transformações no campo ocorreram a partir da década de 1980, sendo que o psicólogo jurídico deixou de ser apenas um perito encarregado de investigações de cunho Rev. Psicol Saúde e Debate. Set., 2020:6(2): 62-79. 
técnico e passou a atuar em outras esferas judiciais, humanizando a área. No intuito de acompanhar tais característica da psicologia forense, o direito contribui com a interpretação das leis das pessoas consideradas deficientes juntamente com outras leis pré-existentes.

\subsection{Direito e Psicologia em evolução: rumo a humanização}

O direito legitima os avanços alcançados por diversas ciências, incluindo os conhecimentos que evoluem em termos da psicologia e inclusão social. Em se tratando de um assunto tão polêmico e controverço, quanto a questão da saúde mental, torna-se necessário retratar sobre aspectos históricos, cruciais à compreensão da evolução e entendimento das leis que regem a questão da capacidade e incapacidade na atualidade.

Desde a promulgação da Lei 180, conhecida como "Lei Basaglia", que proíbe a construção de novos hospitais psiquiátricos e prevê a extinção progressiva dos já instalados e sua substituição por serviços comunitários; vem sendo coroado no campo legal, as experiências assistenciais em Saúde Mental. Houve um laborioso e engenhoso processo de reinserção dos ditos "alienados" na comunidade, ou seja, reinserção dos pacientes internados (sob a lógica da responsabilização da equipe), período em que ocorreu a desativação de hospitais psiquiátricos, dando início a criação e organização dos serviços substitutivos ao manicômio (Basaglia, 1985).

Nesse momento tentavam assegurar aos portadores de sofrimento mental um espaço real de cidadania - ou seja, propiciar-Ihes um lugar de protagonista de suas vidas e de uma transformação social, como legítimos habitantes da cidade. Afirmando-se pela primeira vez ser possível e necessária a extinção do hospital psiquiátrico, dado o fracasso de todos os esforços anteriores para transformá-lo num espaço terapêutico.

$\mathrm{Na}$ história sanitária brasileira, esse Movimento representou uma real revolução nas relações entre a Sociedade e o Estado, que passaram a se realizar a partir de alguns outros referenciais, em que se buscava principalmente a democratização do acesso à saúde. Esse processo, conhecido como Movimento da Reforma Sanitária, juntamente com todo o movimento em prol da redemocratização do Brasil, resultou, entre outros frutos, no planejamento e construção do Sistema Único de Saúde - SUS (Amarante, 2000).

No país, no final da década de 1970, iniciou-se um intenso questionamento sobre os problemas na área da assistência psiquiatria, inicialmente no seio dos trabalhadores, denominado Movimento da Reforma Psiquiátrica.

Breve o movimento se estendeu transformando-se em uma articulação, envolvendo usuários do sistema e seus familiares, vários setores da sociedade civil organizada e a opinião pública, configurando dessa maneira um verdadeiro movimento social denominado Movimento da Luta Antimanicomial. Reivindicavam uma profunda mudança no modelo, envolvendo as ciências, Rev. Psicol Saúde e Debate. Set., 2020:6(2): 62-79. 
as técnicas e a própria cultura vigente em relação a loucura e a deficiênca. Apesar disso, das condições de indignidade e abusos à condição humana perpetradas nos hospitais psiquiátricos, tal realidade ainda faz parte do cenário da assistência psiquiátrica em alguns lugares do Brasil (Lobosque, 1997).

Com o advento de mais uma das iniciativas de reorientação do sistema de saúde brasileiro, as AIS (Ações Integradas de Saúde), em meados da década de 1980, houve significativo ingresso de psicólogos e de outros profissionais para a realização de ações descentralizadas em Saúde Mental em serviços ambulatoriais:

“(...) um compromisso com a criação progressiva das equipes de saúde, ou seja, de contratação de outros profissionais como psicólogos, assistentes sociais, nutricionistas, terapeutas ocupacionais, etc, pois atribuía-se às equipes o papel crítico de reorientação e transformação do sistema de saúde. No mesmo ano, na área da saúde mental, essas mesmas diretrizes passaram a nortear a prática da DINSAM (Divisão Nacional de Saúde Mental), órgão do Ministério da Saúde (...)." (Dimenstein, 1998, p.61).

A atuação daqueles serviços ambulatoriais, descentralizados em centros de saúde, se configurou como a principal modalidade de cuidados em Saúde Mental na Atenção Básica no Brasil até o final da década de 1990.

Apesar de se constituir como alternativa à assistência psiquiátrica hospitalar hegemônica, o modelo ambulatorial de atenção em Saúde Mental desenvolvido na época foi alvo de críticas, como a feita por Lobosque (1997) no trecho a seguir:

“(...) Enquanto os loucos continuam tendo nos hospitais psiquiátricos sua única alternativa de atendimento, os centros de saúde iam criando uma nova clientela de donas-de-casa infelizes e crianças com problemas de aprendizado, que não só preenchia completamente as agendas dos profissionais, como promovia a instituição das famigeradas filas de espera. É preciso aguardar meses para obter uma primeira consulta. O ambulatório não apenas não cumpre a função de esvaziar o hospital, como também psicologiza e psiquiatriza a demanda de toda uma nova camada da população: novos problemas!" (Lobosque, 1997, p.54).

Diversos modelos funcionaram até o modelo atual de assistência aos deficientes e/ou doentes mentais, mas avanços significativos em termos de incapacidade e capacidade estão ocorrendo, sobretudo no sentido de garantirem o exercício da cidadania. Com a promulgação da Lei 13.146/2015, passou a existir uma mitigação, ou, uma relativização no emprego da Teoria das Incapacidades, dado ao fato de que Estatuto da Pessoa com Deficiência amplia o rol dos relativamente incapazes, abrangendo a capacidade civil plena para atos ora não designados relativamente incapazes, permitindo um tratamento mais humanitário.

Rev. Psicol Saúde e Debate. Set., 2020:6(2): 62-79. 
"O Estatuto da Pessoa com Deficiência, [...], busca tornar a teoria das incapacidades - ou das capacidades - mais flexível, mais permeável à ética, mais próxima, enfim, dos princípios normativos e dos direitos fundamentais. A preocupação prioritária do Estatuto foi promover a autonomia e a autodeterminação da pessoa com deficiência. O Estatuto, nesse contexto, reformulou a teoria das incapacidades que tínhamos, e de certo modo a adequou às opções valorativas básicas da Constituição" (Farias, 2017).

A pretensão do Estatuto supracitado é tornar mínima a atuação de terceiros na prática dos atos da vida civil dos que necessitem ser assistidos, permitindo maior expressão da vontade destes. Isto significa, de acordo com o Estatuto, que a deficiência não é causa de incapacidade, como efeito não afeta a plena capacidade do indivíduo, logo a assistência é suplementar à relativa capacidade, como se confere no que está anotado no artigo $6^{0}$ deste Estatuto ${ }^{3}$ e seus incisos, a capacidade relativa não deve atingir os atos aqui listados, somente quando necessário a presença de um terceiro poderá ser atribuída.

O rol presente no artigo $6^{0}$ é exemplificativo, cabendo à pessoa com deficiência, considerada relativamente capaz, a decisão sobre seus atos e quando for imprescindível, solicitar apoio a terceiros e ter garantido assim a essas pessoas a tutela dos seus direitos, o exercício de sua liberdade, e a consequente inclusão destes. Reforçando que quem pratica o ato é a pessoa relativamente capaz, porém assistido caso necessite, pois poderá apresentar dificuldade em face a feitura de atos ou a tomada de decisões.

Para que seja nomeada a pessoa do curador, é imprescindível ser interposta ação judicial pleiteando a Interdição, com o intuito de que se determine a curatela e a consequente declaração da incapacidade ou capacidade relativa da pessoa em vias de interdição. Declarada a sentença, esta deve ser levada a registro público no cartório de pessoas naturais e publicada no sítio do Tribunal a que estiver vinculado o Juízo, e ainda na Plataforma de editais do Conselho Nacional de Justiça. Devendo constar do edital os nomes do Interdito e do Curador, a causa da interdição, os limites da curatela e, não sendo total a interdição, ou seja, interdição parcial, descrever os atos que o interdito poderá praticar autonomamente (Brasil, 2015).

\footnotetext{
${ }^{3}$ Art. 60 A deficiência não afeta a plena capacidade civil da pessoa, inclusive para:

I - casar-se e constituir união estável;

II - exercer direitos sexuais e reprodutivos;

III - exercer o direito de decidir sobre o número de filhos e de ter acesso a informações adequadas sobre reprodução e planejamento familiar;

IV - conservar sua fertilidade, sendo vedada a esterilização compulsória;

$V$ - exercer o direito à família e à convivência familiar e comunitária; e

VI - exercer o direito à guarda, à tutela, à curatela e à adoção, como adotante ou adotando, em igualdade de oportunidades com as demais pessoas (BRASIL. Lei n. 13.146, de 6 de julho de 2015. Estatuto da Pessoa com Deficiência. Diário Oficial da República Federativa do Brasil, Brasília, DF, 7 de julho de 2015. Disponível em: <http://www.planalto.gov.br/ccivil_03/_ato2015-2018/2015/lei/l13146.htm>. Acesso em 25 fevereiro de 2020.)

Rev. Psicol Saúde e Debate. Set., 2020:6(2): 62-79.
} 
São sujeitos da Interdição os pródigos, os ébrios habituais, os viciados em tóxicos e aqueles que por causa transitória ou permanente, não puderem exprimir sua vontade, como aquele em estado comatoso, obesos mórbidos, ou em questões de fragilidade física e mental, limitações sensoriais, ou causas que afetam o psicoequilíbrio, e ainda em processo de internação como a exemplo a internação para tratamento de crises psiquiátricas, dependências químicas, nesse incluindo também o álcool.

Em se tratando de pessoas, causas transitórias são acontecimentos ou fatos que as deixem em estado de relativização da capacidade. Podemos mencionar circunstâncias em que a pessoa se encontre em um estado de debilidade mental em crise, como: amnésia, traumas neurológicos, senilidade, internações compulsórias ou não para tratamentos de dependência química, psiquiátricos, surtos esquizofrênicos ou um estado depressivo que a impossibilite de discernimento adequado.

O que o Ordenamento Jurídico se preocupa nesse contexto é pôr a salvo o bem-estar e a dignidade de pessoas que nesse estado de carência, de apoio à tomada de decisões, que por causa transitória, devido a acontecimentos que deram causa a relativização de sua capacidade, não puder ter a expressão de suas vontades a ser não por vias que não a sua própria. $O$ Ordenamento então busca tutelar os bens jurídicos mais caros à pessoa humana, quais sejam sua capacidade civil e o reflexo de seus atos para exteriorização da vontade deste, quer de natureza patrimonial ou não. Primando em se fazer valer a autodeterminação do indivíduo, a plenificação da capacidade civil, como valores máximos impostos pelo Ordenamento Civil.

As causas transitórias por significado próprio induzem ao entendimento de algo que passa, que se perde no decorrer do tempo. E confiança se tem nos institutos jurídicos, como meio de salvaguardar os carentes do amparo legal. Garantida igualdade de direitos, extirpando o paradigma e o preconceito da deficiência com causa de incapacidade.

Interessante pontuar que as causas transitórias, que privem a pessoa de sua capacidade podem ter como alvo qualquer pessoa, por qualquer fato, e de um instante a outro, sem aviso. Dessa forma, o indivíduo pode do eixo de capaz estar a relativamente incapaz e encontrar sua vontade a deixa de terceiros para a possível concretude de vontades e necessidades, logo: o que antes era simples, o exercício da capacidade, pode num ápice de momento, não mais o ser. O que vai auxiliar nessa tarefa serão as equipes de saúde, que através de relatórios multiprofissionais, de psicólogos, enfermeiros, terapeutas ocupacionais evidenciarão sinais e sintomas de seus pacientes e darão respaldo aos laudos médicos que delimitarão a capacidade ou incapacidade, seja ela momentânea ou não.

No processo de avaliação, que de acordo com Cohen e Swerldik (2006) começa com requisitos específicos de fontes profissionais, exige o uso de questões norteadoras; que no caso deste artigo, enfatiza o laudo do psicólogo. Tal profissional deve estar atento a questão da Rev. Psicol Saúde e Debate. Set., 2020:6(2): 62-79. 
avaliação psicológica, podendo ser realizada através de aplicação de teste, que devem necessariamente estar favorável pelo Conselho Federal de Psicologia para o uso em determinado contexto. Ou seja, o psicólogo deve se ater a legalidade da aplicação dos instrumentos que irá utilizar para determinar sobre aspectos cognitivos e comportamentais do avaliado. E como é sabido em sua formação, estar ciente de medidas, por exemplo, dos índices de confiabilidade e validade publicados no manual do teste. Deve ter em mente o nível de confiabilidade do relatado, alcançado com um determinado grupo de examinandos em determinado contexto. Se um novo grupo pode ser suficientemente diferente ou semelhante ao grupo da amostragem testada na edição do manual. Verificar os estudos efetuados sobre fiabilidade do teste no contexto em que está inserido, ou seja, se o coeficiente de fiabilidade pode ser aceito para o contexto jurídico específico em que está trabalhando (Cohen \& Swerldik, 2006).

Escobar Perez e Cuervo-Martinez (2008) em seu artigo retrata ainda a necessidade de buscar atualização, através de estudos que busquem a validade de instrumentos pelo modelo de avaliação de especialistas. Assim a variável agressividade, por exemplo, não pode apresentar diferenças significativas, entre um especialista que verifica auto-agressividade mais elevada e sem um controle adequado do sujeito, e outro especialista que avalia o mesmo sujeito. Quanto aos pareceres finais, deve haver poucas diferenças, sustentadas por parâmetros preestabelecidos teórica e pragmaticamente. O psicólogo deve dar atenção especial à validade de conteúdo bem realizada de um instrumento, que em uma população diferente fideliza o teste à cultura do sujeito avaliado.

Em fim, na validade de conteúdo retratada por Escobar-Perez e Cuervo-Martinez (2008) ao destacarem a validade obtida do "JUICIO DE EXPERTOS", enfatiza-se a importância do consenso não só do ponto de vista do uso e escolha dos instrumentos, mas também das medidas padrões de aprovação na hora de avaliar um sujeito, se apresenta capacidade ou não de exercer seus atos civis, e em que amplitude, no caso da capacidade transitória.

Sendo assim, a atuação cuidadosa do legislador, interpretação subjetiva de uma equipe multidisciplinar, depende de diversas instâncias, incluindo a perícia do psicólogo forense, para uma aplicação justa dos instrumentos que possui como recursos legais e do Mandamento Legal. Em comunhão com os anseios do melhor cuidado à pessoa que por causa transitória ou permanente, não puder exprimir sua vontade, contribuem enormemente para o engrandecimento da projeção do Princípio da Dignidade Humana, do Respeito, da Equidade e do que se pretende ao aplicar e vivenciar sobre igualdade de direitos, onde uma sociedade mais justa é anseio de todos.

Rev. Psicol Saúde e Debate. Set., 2020:6(2): 62-79. 


\section{CONSIDERAÇÕES FINAIS}

Uma crítica que se faz à Psicologia jurídica, quando efetivada de forma simplista, é que ela acaba por reforçar o lado negativo do Direito, ou seja, a exclusão dos diferentes. Assim, não cabe à Psicologia julgar, mas ser complementar, avaliativa, em relação às demandas jurídicas, jamais querer suplantá-lo ou se colocar como subserviente a ele.

O psicólogo deve prezar pelo princípio da autonomia teórico-técnica e ético- profissional, explicando e informando ao periciando sobre o objetivo, esclarecimento das técnicas utilizadas, data e local da avaliação pericial psicológica. O sigilo dos documentos e avaliações é de total responsabilidade do psicólogo e, quando atuar em equipe multidisciplinar, deve fornecer informações estritamente necessárias às intervenções específicas àquele profissional.

A área de atuação do psicólogo forense engloba contextos variados como a avaliação forense de vítimas e arguidos em processos de crime, de pais e filhos na questão de responsabilidade parental, também em processos de adoção, avaliação de danos póstraumáticos, avaliações nos âmbitos de proteção de crianças e no âmbito tutelar e da curatela.

É necessário enfatizar que, no exemplo, do processo de avaliação psicológica realizado com o objetivo de verificar características antissociais e psicopatas, deve-se manter sempre uma observação focada nos comportamentos do examinando, desde a sua entrada na sala do exame até a sua saída. Os indivíduos que apresentam tais traços comportamentais são manipuladores, portanto tendem a controlar suas falas durante a perícia, em suas respostas e em suas reações, dissimulando e simulando atitudes, tornando assim essencial a utilização de testes psicológicos para fornecer materiais de diagnósticos adicionais.

A Psicologia busca a compreensão das ações humanas, desde uma perspectiva individual até aquela que investiga os seus contextos socioculturais, enquanto o Direito busca normas e parâmetros já legitimados pela sociedade para fundamentar suas decisões.

Apesar de existirem opiniões divergentes, a grande maioria da literatura invade-nos com casos de sucesso em que a Psicologia operou com a Justiça, revelando-se um instrumento de grande utilidade no auxílio da tomada de decisão judicial em processos de difícil julgamento.

Importante salientar que os psicólogos forenses não aplicam a sua atuação somente na vertente de Justiça penal, mas também se debruçam sobre matéria cível, sendo esta relevante na investigação da capacidade civil do indivíduo. O psicólogo forense também deve fornecer a sua experiência nas oitivas de crianças e adolescentes, perícia e avaliação do dano psicológico, na discriminação no emprego, na deficiência mental, no compromisso civil, nas questões psicológicas que afetem o devido processo legal, tais como depoimentos de testemunhas oculares e a escolha do júri.

Rev. Psicol Saúde e Debate. Set., 2020:6(2): 62-79. 
De fato, a psicologia forense é uma área bastante ampla e que exige preparação do profissional que busca atuar neste campo. Dessa forma, os profissionais forenses, no seu dia a dia, podem ser afetados pelas ocorrências que envolvem questões pessoais, sobretudo a que geram grandes abalos emocionais, por vezes sentindo-se pressionados por situações do trabalho. Os profissionais da área devem pensar em sua saúde ocupacional, desta forma, sobretudo o psicólogo deve se atentar e manter um equilíbrio emocional no ambiente jurídico, já que necessita ser um profissional ativo na função e ainda proporcionar segurança para os outros, geralmente lidando com equipe multidisciplinar.

Especificamente sobre a Teoria das Capacidades, foco no presente trabalho, analisa-se o que torna as pessoas diferentes, em que se classifica os mais capazes dos menos capazes. Através de uma perspectiva histórica, sobretudo à luz da luta anti-manicomial foi retratada a evolução do conceito de saúde mental e a questão polêmica em torno da inclusão social, sem deixar de lado o viés cultural. Percebe-se que o ordenamento jurídico amparado em laudos e pareceres de psicólogos e equipes de saúde qualificadas, buscam meios de tutelar os interesses de todos, com equidade, uma das formas de integração do direito, considerando os desiguais dentro de sua desigualdade.

A pretensão do Estatuto da Pessoa com Deficiência é a clara busca da inclusão de pessoas ora portadoras de deficiências ou que portem algum limite ao uso de suas capacidades, de modo a garantir o maior acatamento ao Princípio da Dignidade da Pessoa Humana, princípio constitucional no qual deve-se nortear todas as ações e esforços buscando o melhor convício social e respeito mútuo. É um trabalho conjunto, entre equipe de saúde e ordenhamento jurídico que tornará a coexistência melhor, um universo jurídico mais respeitável em que todos possam se perceber iguais em tratamento e dignidade.

Ressalta-se que a sistemática das incapacidades passou a ser flexibilizada, que com certa maleabilidade passou a pensar as circunstâncias do caso concreto e suas peculiaridades, para então operar tutelando a dignidade, a interação social e da inclusão de pessoas com deficiência ou doença mental. De um sistema rígido e taxativa a um incessante trabalho para um tratamento mais individualizado e atencioso, em que se preze o atendimento e o cuidado específico.

Quanto ao laudo do psicólogo, a avaliação pericial, seja para determinar a capacidade, ou incapacidade relativa, tem como premissa atuar de forma padronizada, através de jurisprudências e experiências compartilhadas por especialistas, com o objetivo de diminuir a probabilidade de significativas discordâncias entre peritos. Quando se consideram a falta de padronização dos instrumentos utilizados por psicólogos nas avaliações, conclui-se a necesidade de se realizar um inquérito na avaliação psicológica, a fim de atendendem aos processos cognitivos, emocionais e comportamentais respeitando-se a evolução dos construtos, avaliando-se a cultura e por com seguinte as leis que regem esse contexto psicosociocultural. Sugere-se que os especialistas Rev. Psicol Saúde e Debate. Set., 2020:6(2): 62-79. 
estabeleçam critérios de forma a abarcar medidas e comportamentos diferentes para diferentes tipos de categorias: sujeitos absolutamente incapazes e relativamente incapazes, suscitando causas transitórias ou permanentes.

Dessa forma, para uma equipe multidisciplinar, em que estão presentes médicos, psicólogos, enfermeiros e outros especialistas, avaliar o indivíduo de forma a delimitar estados de higidez mental momentânea, torna-se algo desafiante, sobretudo em processos jurídicos nos quais laudos específicos são necessários. O que vem sido sugerido como prática jurídica é que esses laudos sejam emitidos de forma periódica, tendo como respaldo instrumentos de avaliação como testes e exames fidedignos, validados para cada especificidade de caso. 


\section{REFERÊNCIAS}

Amarante, P. (2000) Loucos pela vida: Trajetória da Reforma psiquiátrica no Brasil. 2 edição. Rio de Janeiro: Editora Fiocruz.

Androvandi, C., Serafini, A. J., Trentini, C. M., \& Coelho, E. (2007) Imputabilidade penal, capacidade cognitiva e instrumentos de medida psicológica. Revista Psicologia em Foco. Disponível em: <http://revistas.fw.uri.br/index.php/psicologiaemfoco/article/view/1127/1599>. Acesso em 25 fevereiro de 2020.

Basaglia, F. (1985). As Instituições da Violência. In: BASAGLIA, F. (org). A Instituição Negada. Rio de Janeiro: Edições Graal, pp. 99-134.

Brasil. Lei n. 10.406, de 10 de janeiro de 2002. Código Civil. Diário Oficial da República Federativa do Brasil, Brasília de 11 de janeiro de 2002. Disponível em: <http://www.planalto.gov.br/ccivil_03/leis/2002/L10406compilada.htm>. Acesso em 25 fevereiro de 2020.

Brasil. Lei n. 13.105, de 16 de março de 2015. Código de Processo Civil. Diário Oficial da República Federativa do Brasil, Brasília, DF, 17 de março de 2015 . Disponível em:<http://pesquisa.in.gov.br/imprensa/jsp/visualiza/index.jsp?data=17/03/2015\&jornal=1\&pag ina $=1$ \&totalArquivos=128>. Acesso em 25 fevereiro de 2020 .

Brasil. Lei n. 13.146, de 6 de julho de 2015. Estatuto da Pessoa com Deficiência. Diário Oficial da República Federativa do Brasil, Brasília, DF, 7 de julho de 2015. Disponível em: <http://www.planalto.gov.br/ccivil_03/_ato2015-2018/2015/lei/113146.htm>. Acesso em 25 fevereiro de 2020.

Brasil. Lei n. 3.071, de 1ำ de janeiro de 1916. Código Civil. Diário Oficial da República Federativa do Brasil, Brasília de 01 de janeiro de 2016. Disponível em: <http://www.planalto.gov.br/ccivil_03/leis/L3071.htm>. Acesso em 25 fevereiro de 2020.

Cohen \& Swerldik (2006). Pruebas y evaluación psicológicas. Introducción a las pruebas y a la medición. (Sexta edición).

Devera, D. \& Costa-Rosa, A. (2007). Marcos Históricos da Reforma Psiquiátrica Brasileira: Transformações na legislação, na ideologia e na práxis. Revista de Psicologia da UNESP. São Paulo. 6, n. 1, pp. 60-79.

Dimenstein, M. D. B. (1998). O psicólogo nas Unidades Básicas de Saúde: desafios para a formação e atuação profissionais. Estudos de Psicologia. Natal: v.3, n.1, pp. 53-81.

Escobar Perez \& Cuervo-Martinez (2008) Validez de contenido y Juicio de Expertos: uma aproximación a su utilización. Universidad El Bosque, Colombia. Institucion Universitaria Iberoamericana, Colombia. Avances en Medición, 6, 27-36

Farias, C. C. (2017). Manual de Direito Civil - Volume Único / Cristiano Chaves de Farias, Felipe Braga Netto, Nelson Rosenvald - Salvador: JusPodivm. pp. 300

Fiorelli, J. O. \& Mangini, R. C. R. (2020). Psicologia Jurídica. $10 \stackrel{a}{a}$ ed. São Paulo: Atlas.

Lobosque, A. M. (1997). Princípios para uma Clínica Antimanicomial. Saúde Loucura; 13. São Paulo: Hucitec.

Rev. Psicol Saúde e Debate. Set., 2020:6(2): 62-79. 
Monteiro, W. B. \& Pinto, A. C. B. M. (2009). Curso de Direito Civil, v,1: parte geral - 42ª ed. São Paulo: Saraiva.

Rosenvald, N. \& Farias, C. C. (2014). Curso de Direito Civil, v, 6: Direito de Famílias - 6a ed. Salvador: jusPODIVM.

Rosenvald, N. (2016). EPM conclui o curso "Temas atuais do Direito das Famílias e das Sucessões", Revista Eletrônica da Escola Paulista da Magistratura, ${ }^{\circ}$ 225. Disponível em: <http://epm.tjsp.jus.br/Noticias/noticia/34766>. Acesso em 25 fevereiro de 2020.

Serafim, A.P, Barros, D. M. \& Rigonatti, A. P. (2006). Temas em Psiquiatria Forense e Psicologia

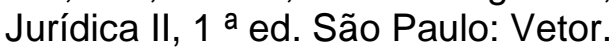

Varela, O. H., Alvarez, H. R. \& Sarmiento, A. J. (2000). Psicologia Forense: Consideraciones sobre Tematicas Centrales. Buenos Aires: Abeledo Berrot. 